\title{
Non Alcoholic Fatty Liver Disease Patients Attending Two Metropolitan Hospitals in Melbourne, Australia; High Risk Status and Low Prevalence
}

Running title: NAFLD clinical prevalence and severity

\author{
Elena S George ${ }^{1,2,3}$, Stuart K Roberts ${ }^{4}$, Amanda J Nicoll ${ }^{5}$, Anjana Reddy ${ }^{1}$,Tonya Paris ${ }^{1}$, \\ Catherine Itsiopoulos ${ }^{1}$, Audrey C Tierney ${ }^{1,2,5}$
}

1. Department of Rehabilitation, Nutrition and Sport, La Trobe University, Bundoora, VIC, Australia, 2. Department of Nutrition, Alfred Health, Commercial Rd, Prahran, VIC, Australia, 3. School of Exercise and Nutrition Sciences, Deakin University, Geelong, Australia, 4. Department of Gastroenterology, Alfred Health, Commercial Rd, Prahran, VIC, Australia, 4. Department of Gastroenterology, Eastern Health, Arnold Street, Box Hill, VIC, Australia, 5. Department of Clinical Therapies, University of Limerick, Limerick, V94 T9PX, Ireland.

Corresponding author: Elena S George, B Food Sc \& Nutr (Hons), MDiet

Building J, Deakin University, 221 Burwood Hwy, Burwood VIC 3125, Telephone: +61 (0) 3 9246 8622, Email: Elena.George@deakin.edu.au

Author details (positions at time of submission): Elena S George: Honorary Research Fellow La Trobe University, Lecturer Deakin University, Stuart K Roberts: Head of Hepatology, Alfred Health, Amanda J Nicoll: Director Gastroenterology, Eastern Health, Anjana J Reddy: PhD candidate La Trobe University, Tonya Paris: Dietitian, Catherine Itsiopoulos: Head of

This is the author manuscript accepted for publication and has undergone full peer review but has not been through the copyediting, typesetting, pagination and proofreading process, which may lead to differences between this version and the Version of Record. Please cite this article as doi: 10.1111/imj.13973

This article is protected by copyright. All rights reserved. 
School, Allied Health, La Trobe University, Audrey Tierney: Senior Lecturer La Trobe

University and Limerick University.

Requests for reprints should be requested from the corresponding author.

Conflict of interest: None declared.

Contribution: ESG conceptualised the study. ESG, AR and TP were involved in data collection. ESG drafted the manuscript. All authors provided intellectual input and critically reviewed the manuscript.

Source of funding: This work was supported by an Australian Government Research Training Program Scholarship (ESG).

Word Count:

Abstract- 247

Manuscript- 3158

Introduction

Non-Alcoholic Fatty Liver Disease (NAFLD) is prevalent in approximately $20-30 \%$ of populations in developed countries ${ }^{1}$, with rates reported as high as $40-90 \%$ in subgroups with Type 2 diabetes mellitus (T2DM) and obesity. ${ }^{2,3}$ Prevalence rates may be underestimated as the condition is asymptomatic and often goes undiagnosed and untreated until it has progressed. Insulin resistance (IR) is the underlying pathological 
mechanism in NAFLD, often referred to as the hepatic manifestation of metabolic syndrome. NAFLD occurs alongside hyperlipidaemia, abdominal obesity and/or hypertension. ${ }^{4}$ NAFLD is an independent risk factor for cardiovascular disease (CVD); which is the leading cause of mortality in affected patients. ${ }^{5,6}$ Approximately $20 \%$ of NAFLD patients will develop the progressive form of the disease, non-alcoholic steatohepatitis (NASH). Individuals with NASH and liver fibrosis are at increased risk of end stage liver disease, hepatocellular carcinoma $(\mathrm{HCC})$ as well as all-cause mortality. ${ }^{7-10}$ Despite the high prevalence and risks associated with the disease, safe and effective, evidence based prevention and management strategies are lacking.

The diagnosis and staging of NAFLD is challenging as the gold standard for NASH and NAFLD related fibrosis is liver biopsy ${ }^{11}$, and increasingly less precise methods such as serological/biochemistry scores, ultrasound and transient elastography (TE) are used. ${ }^{9,11-13}$ Serological scoring systems and TE have an acceptable reliability at distinguishing cirrhosis from non-cirrhosis. ${ }^{11,14,15,16}$ Ultrasound only identifies established cirrhosis and cannot be used to accurately stage disease or monitor progression. ${ }^{13}$

Simple steatosis in NAFLD can be reversed with lifestyle modifications, preventing the progression to NASH and cirrhosis ${ }^{7,17,18}$; however, many patients are not identified until they have advanced disease. High risk groups with T2DM have a significant prevalence of 
liver injury as determined by TE. ${ }^{19}$ Earlier detection and management ${ }^{20}$ may prevent progression, with NAFLD projected to be the leading reason for liver transplant in $2020 .^{21,22}$

The aim of this observational study is to determine the rates and characteristics of NAFLD patients referred to liver clinics in two metropolitan hospitals in Melbourne, Australia. We hypothesise that in the absence of established screening practices and treatments, patients with NAFLD referred to and attending liver clinics for monitoring, will represent a minority of the patient cohort and have progressed liver disease and established co morbidities.

\section{Materials and Methods}

\section{Study participants and design}

Liver clinic appointment lists were prospectively screened weekly at two metropolitan hospitals in Melbourne, Australia to determine eligibility for a randomised controlled dietary intervention trial in NAFLD subjects. ${ }^{23}$ Data was collected for ten consecutive months at each respective site between October 2014 and June 2016. All patients aged $\geq 18$ years were included, and the primary reason for clinic attendance was recorded. NAFLD diagnosis was based on the following: (1) sonographic diagnosis of fatty liver, defined as diffusely increased liver echogenicity (>right renal parenchyma) with vascular blurring; or biopsy proven fatty liver disease; and (2) a negative history of alcohol consumption exceeding current Australian health guidelines ${ }^{24}$; and (3) exclusion of liver disease of other aetiology including drug-induced, autoimmune, viral hepatitis, cholestatic, metabolic and genetic liver disease.

This article is protected by copyright. All rights reserved. 
Available results including liver tests, lipid profile, glucose, $\mathrm{HbA} 1 \mathrm{c}$, insulin, anthropometry, liver imaging, biopsies, comorbid diagnoses and medications were obtained from medical records. Records were cross checked for duplicate appointments. The most recent test results were included for assessment. Body mass index (BMI) was calculated $\left(\mathrm{kg} / \mathrm{m}^{2}\right)$ and obesity was defined as $\mathrm{BMI} \geq 30 \mathrm{~kg} / \mathrm{m} .{ }^{2,25}$ Homeostatic Model of Assessment (HOMA), a measure of IR was calculated using the formula [glucose ( $\mathrm{mmol} / \mathrm{I})$ multiplied by insulin $(\mu \mathrm{U} / \mathrm{ml}) / 22.5]{ }^{26}$

The study was approved by Alfred Health, Eastern Health and La Trobe University Human Research Ethics Committees.

\section{Statistical analysis}

Analysis was performed using the statistical package SPSS 23 (SPSS Inc., 1989-2004, Chicago, IL, USA). Normality of continuous variables was assessed using KolmogorovSmirnov test. All data are expressed as mean \pm standard deviation or median (IQR), as appropriate. For continuous data, comparisons between groups were assessed using independent t-tests or one way ANOVA in parametric variables and the Wilcoxon rank sum test/Mann-Whitney $U$ test or Kruskal-Wallis test, in non-parametric variables. Categorical 
variables were compared by independent $\chi^{2}$ test. A two-sided $p$-value of $<0.05$ was considered to be statistically significant. Pearson and Spearman rank correlation coefficient was used to assess strength and significance of association between variables. A Bonferroni correction was used for post hoc test analysis. The relationship between LSM and correlated predictors was assessed using multiple and univariate regression analysis.

\section{Results}

There were a total of 2050 patients across two liver clinics during the 10 month period who were screened for this study regardless of clinic attendance (Figure 1). These clinics captured all NAFLD outpatients in the Liver clinics with the exception of those seen privately. Prevalence of medical diagnoses at the clinics are listed in Table 1 . There were 148 (7\%) patients managed for NAFLD. The commonest reason for clinic attendance was management of Chronic Hepatitis B (20\%), alcoholic fatty liver disease (18\%) and Chronic Hepatitis C (13\%). Autoimmune hepatitis, haemochromatosis and Primary Biliary Cholangitis represented $5 \%, 2 \%$ and $2 \%$ of clinic attendance, respectively, with other conditions comprising $\leq 1 \%$.

NAFLD was predominantly reported with ultrasound showing consistent radiologic features (81\%). Thirteen (9\%) patients had NAFLD diagnosed by liver biopsy, with advanced liver fibrosis (F3) on three, cirrhosis (F4) in seven. A Brunt score was only available for 9 (6\%) patients and scores ranged from 4-7 (supplementary table). A large proportion of patients 
had TE, Fibroscan ${ }^{\mathrm{TM}}$ (79\%), and various liver biochemical measures were available in 78 $97 \%$ of patients.

\section{Group characteristics}

The demographic, clinical and laboratory characteristics of patients with NAFLD are described in Table 2 . There were slightly more females (56\%) and the median BMI was 30.7 $\pm 5.9 \mathrm{~kg} / \mathrm{m}^{2}$, with $32 \%$ overweight and $40 \%$ obese. The median LSM score was $6.5(6.0) \mathrm{kPa}$; $18 \%$ of patients with NAFLD had a LSM score greater than $12 \mathrm{kPa}$, and $7 \%$ greater than $20 \mathrm{kPa}$, suggestive of advanced fibrosis and cirrhosis, respectively. The median alanine aminotransferase (ALT) level was elevated with significantly higher for males than females, $(p=0.01)$. NAFLD patients were overall IR with a median HOMA score of $4.2(3.2)$.

The presence of co-morbidities within the group are included in Table 2 Of the NAFLD patients, 44\% had T2DM and an additional 10\% had impaired glucose tolerance, $52 \%$ had hypertension, and $20 \%$ had a diagnosis of cardiovascular disease (CVD). Oral hypoglycaemic agents (OHAs), statins and antihypertensive medications were reported in $35 \%, 30 \%$ and $37 \%$ of the cohort, respectively.

Liver Stiffness Measure (LSM) Score

This article is protected by copyright. All rights reserved. 
The cohort were further categorised according to liver disease severity based on a LSM cutoff score of $<$ or $\geq 9.6 \mathrm{kPa}$, a value that has a positive predictive value for advanced fibrosis of $72 \% .{ }^{27}$ (Table 2). Patients with NAFLD in the higher LSM group were older (mean age $59.9 \pm$ 12.2 vs. $52.9 \pm 14.5$ years, $p=0.006)$ and had significantly higher BMI ( $32.5 \pm 6.4$ and 29.6 $\pm 5.5 \mathrm{~kg} / \mathrm{m} 2, p=0.02)$. Those with higher LSM scores also had higher median AST scores (40.0 \pm 58.0 vs. $25.0 \pm 33.3 \mathrm{u} / \mathrm{L}, p=0.0005)$. Median HOMA scores were significantly higher indicating that the group with higher LSM scores were more IR $(5.1 \pm 2.6$ vs.3.1 $\pm 3.2, p=$ 0.03). Total and low density lipoprotein (LDL) cholesterol were lower in this group with higher LSM ( $4.6 \pm 1.3$ vs. $5.2 \pm 1.1 \mathrm{mmols} / \mathrm{L}, p=0.01$ and $1.1 \pm 1.1$ vs. $3.1 \pm 1.0 \mathrm{mmol} / \mathrm{L}$, $p=0.031$ respectively), and there was a higher use of statins in this group ( $25 \%$ vs $30 \%$, $p=0.54)$. The group with higher LSM scores had greater rates of T2DM and hypertension; $33 \%$ vs $58 \%, p=0.009$ and $43 \%$ vs $65 \%, p=0.023$, respectively. Of note, there were 27 NAFLD patients with LSM scores $>12 \mathrm{kPa}$, a score consistent with cirrhosis. ${ }^{28}$

LSM scores significantly increased with increasing BMI; (mean LSM in healthy weight $5.6 \mathrm{kPa}$ \pm 3.4 , overweight $5.6 \mathrm{kPa} \pm 5.3$, obese $6.6 \mathrm{kPa} \pm 9.4$ and morbidly obese $9.9 \mathrm{kPa} \pm 9.1, p=$ 0.032). Significantly higher LSM scores were observed in those with a diagnosis of NAFLD and T2DM (32\%) compared to NAFLD patients without T2DM (47\%); median 8.5 (11.6) vs. $5.9(5.2) \mathrm{kPa}, p=0.011$, respectively. Patients with NAFLD and hypertension (52\%) had 
significantly higher LSM scores than normotensive NAFLD patients; median of 8.2 (8.8) kPa vs. 5.7 (4.6) $\mathrm{kPa}, p=0.011$, respectively.

\section{Associations of variables with LSM scores}

Correlational analysis was performed to assess the strength of associations between age, $\mathrm{BMI}$ and biochemical variables with LSM score. Table 3 displays the degree to which these variables correlate. The strongest correlations were reported for LSM score and HOMA $(r=0.49, p=0.008)$, and LSM and AST; $(r=0.42, p=0.0005)$. Correlations between BMI $(r=0.27$ $p=0.005)$, age $(r=0.28 p=0.002), \operatorname{ALT}(r=0.20 p=0.03)$ and LDL $(r=-0.33 p=0.002)$ showed weaker, albeit significant, associations with LSM.

\section{Regression Analysis}

A multiple regression analysis of LSM was conducted and showed that age, BMI, AST, ALT, total cholesterol and LDL cholesterol remained significant. The model indicated these variables explained $29.3 \%$ of the variance $\left(R^{2}=0.293, F(6,81)=5.59, p<0.0005\right)$. BMI, age and AST levels positively and significantly predict $\operatorname{LSM}$ score $(\beta=0.30, p=0.003 ; \beta=0.38$, $p=0.0005 ; \beta=0.23, p=0.017$, respectively). 
A separate univariate linear regression was conducted with HOMA as a predictor. This was not entered in the previous model as only 32 participants had a HOMA score. The regression equation with HOMA was significant, $R^{2}=0.15$, adjusted $R^{2}=0.12, F(1,27)=4.89, p<0.036$.

\section{Discussion}

This observational study showed that NAFLD constituted a minority of the liver clinic population, and NAFLD patients were predominantly obese with $I R$, and had elevated liver enzymes and TE LSM scores consistent with mild fibrosis. Over half of the NAFLD patient group had T2DM, impaired glucose tolerance and hypertension, with $20 \%$ of the cohort diagnosed with CVD. Therefore, while NAFLD is highly prevalent in the community, this study demonstrated that it does not make up a large proportion of patients at established liver clinics. Low representation of this disease and management of the condition in the clinical setting is likely attributed to a number of factors; particularly in relation to its asymptomatic nature, the lack of routine screening practices of high risk groups for NAFLD in the community, clinic fatigue by these patients, and low rates of referrals to hepatology services by clinicians of those with suspected NAFLD. ${ }^{29,} 30$ It is likely that the latter is related in part to an absence of pharmacological therapies for the disease.

Definitive diagnosis and staging are problematic, as biopsy is expensive, invasive and not without risk ${ }^{12}$, explaining the low biopsy rate in this study (14\%). Despite 
recommendations, liver biopsy It is not a viable screening tool for at risk patients, such as those with T2DM and NAFLD. ${ }^{31}$ Routine biochemistry and ultrasound are of limited use in this group, as they do not necessarily correlate with the severity of the liver disease ${ }^{32}$, and liver biochemistry elevation significantly underestimates the true prevalence of NAFLD and do not predict liver histology. ${ }^{1,33}$ TE using Fibroscan ${ }^{\mathrm{TM}}$ is a rapid non-invasive technique that is able to estimate the likelihood of significant liver fibrosis using LSM. It is particularly helpful in identifying the group with probable cirrhosis, but is less reliable in lesser degrees of fibrosis. However, in NAFLD it is less reliable than other liver diseases as success rates are lower in obese individuals when compared to non-obese counterparts. ${ }^{28}$ In this study, individuals with higher LSM scores were obese, had raised liver enzymes, were IR, and had significantly higher rates of HTN. The finding that elevated LSM was associated with decreased total cholesterol is consistent with previous literature. ${ }^{34}$

NAFLD characteristically exists in a setting of altered metabolism, comprising abdominal obesity, IR, dysglycaemia and atherogenic dyslipidaemia, similar to CVD ${ }^{35}$, 36. This study highlights the elevated risk of progression to liver related complications and CVD, in patients with these features ${ }^{11}$ Serological scoring systems may also be a non-invasive and rapid method to differentiate between NAFLD patients with and without advanced liver fibrosis. ${ }^{14}$ ${ }^{15}$ However, required data to calculate such scores was not available for this cohort. 
This cross sectional study shows that referral and management of patients with NAFLD in the tertiary setting is not optimal, based on the known community prevalence of the condition. Australian data reflective of metropolitan areas for this age group (mean 55 years) reiterates this point, estimating that in both males and females prevalence is likely to be $25-30 \%$ of the population. ${ }^{37,38}$

Over half of the NAFLD patients in this study had T2DM or IGT. NAFLD poses an increasing risk of overall mortality compared to the general population (standardized mortality ratio 1.34) and T2DM poses an additional risk factor for death. ${ }^{7,39} 40$ The presence of T2DM increases the CVD risk, and has consistently been shown to be a key predictor of NASH and advanced fibrosis. ${ }^{41-43}$ However, it may be impractical to propose screening of all T2DM for significant liver disease. Similar to previous reports, our study showed a strong positive association with IR and LSM, consistent with other evidence of more severe liver disease in T2DM and IR. ${ }^{39}, 44-46$

At present there is no data available on the prevalence of NAFLD within individual Australian States and Territories. It is likely that in rural areas and/or those with higher rates of indigenous populations such as the Northern Territory and Western Australia, that prevalence of NAFLD may be even higher. Strategies to engage these patients in the community with particular attention to people with T2DM and obesity should be 
considered, with an economic cost benefit analysis to ascertain better investment of resources at the subclinical level of disease. Patient access to the tertiary setting is also important as it provides increased access to new and promising therapies as part of clinical trials. Multidisciplinary clinics for high risk patients such as those with T2DM, may be one such strategy to ensure screening and management of NAFLD. This would encompass hepatologists and dietitians present during diabetes clinics.

The strengths of this cross sectional study were that two major metropolitan hospitals were screened weekly for 10 months capturing a cohort of over 2,000 liver clinic patients, a generalizable subsample of the Melbourne clinical NAFLD patient group. However biopsy data was infrequent, and diagnosis and staging relied on biochemistry and TE, with their previously mentioned limitations ${ }^{28}$.

The main limitation of this study is that the overall sample size of patients with NAFLD was small, with missing laboratory values affecting some outcomes. The observational design also meant there was unavailable data for assessment of disease severity using serological scoring systems. For most patients, liver injury was staged using TE which has limitations in obese patients and those with less advanced liver disease. ${ }^{9,11}$

\section{Conclusion}

In conclusion, patients with NAFLD referred and managed in metropolitan liver clinics from two major hospitals constitute a minority of the Liver Disease population engaged in tertiary 
level health care, despite high rates of NAFLD in Australia. Participants in this study with NAFLD had multiple components of the metabolic syndrome including being overweight, IR, and with almost $20 \%$ having TE levels suggestive of cirrhosis. Given the large proportion of the population with NAFLD and the small numbers captured in these clinical settings, screening of high risk patients such as those with diagnosed diabetes, cardiovascular risk factors or who are obese, is warranted to ensure earlier detection of the disease. As biopsy is invasive, surrogate markers such as TE and HOMA scores which are rapid and easily attainable should be considered. 


\section{References}

1. Younossi ZM, Koenig AB, Abdelatif D, Fazel Y, Henry L, Wymer M. Global Epidemiology of Non-Alcoholic Fatty Liver Disease-Meta-Analytic Assessment of Prevalence, Incidence and Outcomes. Hepatology. 2015;64(1):73-84.

2. Williamson RM, Price JF, Glancy S, Perry E, Nee LD, Hayes PC, et al. Prevalence of and risk factors for hepatic steatosis and nonalcoholic Fatty liver disease in people with type 2 diabetes: the Edinburgh Type 2 Diabetes Study. Diabetes care. 2011;34(5):1139-44.

3. Ortiz-Lopez C, Lomonaco R, Orsak B, Finch J, Chang Z, Kochunov VG, et al. Prevalence of Prediabetes and Diabetes and Metabolic Profile of Patients With Nonalcoholic Fatty Liver Disease (NAFLD). Diabetes Care. 2012;35(4):873-8.

4. Armstrong MJ, Houlihan DD, Bentham L, Shaw JC, Cramb R, Olliff S, et al. Presence and severity of non-alcoholic fatty liver disease in a large prospective primary care cohort. Journal of hepatology. 2012;56(1):234-40.

5. Targher G, Byrne CD, Lonardo A, Zoppini G, Barbui C. Non-alcoholic fatty liver disease and risk of incident cardiovascular disease: A meta-analysis. J Hepatol. 2016;65(3):589-600.

6. Lonardo A, Sookoian S, Pirola CJ, Targher G. Non-alcoholic fatty liver disease and risk of cardiovascular disease. Metabolism. 2016;65(8):1136-50.

7. Adams LA, Lymp JF, Sauver JS, Sanderson SO, Lindor KD, Feldstein A, et al. The natural history of nonalcoholic fatty liver disease: a population-based cohort study. Gastroenterology. 2005;129(1):113-21.

8. Ekstedt M, Franzén LE, Mathiesen UL, Thorelius L, Holmqvist M, Bodemar G, et al. Long-term follow-up of patients with NAFLD and elevated liver enzymes. Hepatology. 2006;44(4):865-73.

9. Musso G, Gambino R, Cassader M, Pagano G. Meta-analysis: natural history of non-alcoholic fatty liver disease (NAFLD) and diagnostic accuracy of non-invasive tests for liver disease severity. Annals of medicine. 2011;43(8):617-49.

10. Söderberg C, Stål P, Askling J, Glaumann H, Lindberg G, Marmur J, et al. Decreased survival of subjects with elevated liver function tests during a 28-year follow-up. Hepatology. 2010;51(2):595602.

11. Friedrich-Rust M, Ong MF, Martens S, Sarrazin C, Bojunga J, Zeuzem S, et al. Performance of transient elastography for the staging of liver fibrosis: a meta-analysis. Gastroenterology. 2008;134(4):960-74. e8.

12. Spengler EK, Loomba R. Recommendations for Diagnosis, Referral for Liver Biopsy, and Treatment of Nonalcoholic Fatty Liver Disease and Nonalcoholic Steatohepatitis. Mayo Clinic Proceedings. 2015;90(9):1233-46.

13. Mishra $P$, Younossi ZM. Abdominal ultrasound for diagnosis of nonalcoholic fatty liver disease (NAFLD). The American journal of gastroenterology. 2007;102(12):2716-7.

14. McPherson S, Stewart SF, Henderson E, Burt AD, Day CP. Simple non-invasive fibrosis scoring systems can reliably exclude advanced fibrosis in patients with non-alcoholic fatty liver disease. Gut. 2010;59(9):1265-9.

15. Angulo $P$, Bugianesi E, Bjornsson ES, Charatcharoenwitthaya $P$, Mills PR, Barrera F, et al. Simple noninvasive systems predict long-term outcomes of patients with nonalcoholic fatty liver disease. Gastroenterology. 2013;145(4):782-9. e4.

16. Yoneda $\mathrm{M}$, Yoneda $\mathrm{M}$, Mawatari $\mathrm{H}$, Fujita $\mathrm{K}$, Endo $\mathrm{H}$, lida $\mathrm{H}$, et al. Noninvasive assessment of liver fibrosis by measurement of stiffness in patients with nonalcoholic fatty liver disease (NAFLD).

This article is protected by copyright. All rights reserved. 
Digestive and liver disease : official journal of the Italian Society of Gastroenterology and the Italian Association for the Study of the Liver. 2008;40(5):371-8.

17. Kaser S, Ebenbichler CF, Tilg H. Pharmacological and non-pharmacological treatment of nonalcoholic fatty liver disease. International Journal of Clinical Practice. 2010;64(7):968-83.

18. George ES, Tierney AC, Campbell KL, Macdonald GA, Hickman IJ. What Is the Optimal Dietary Composition for NAFLD? Current Hepatology Reports. 2017.

19. Casey SP, Kemp WW, McLean CA, Topliss DJ, Adams LA, Roberts SK. A prospective evaluation of the role of transient elastography for the detection of hepatic fibrosis in type 2 diabetes without overt liver disease. Scand J Gastroenterol. 2012;47(7):836-41.

20. Ginès $P$, Graupera I, Lammert F, Angeli $P$, Caballeria L, Krag A, et al. Screening for liver fibrosis in the general population: a call for action. The Lancet Gastroenterology \& Hepatology. 2016;1(3):256-60.

21. Charlton MR, Burns JM, Pedersen RA, Watt KD, Heimbach JK, Dierkhising RA. Frequency and outcomes of liver transplantation for nonalcoholic steatohepatitis in the United States.

Gastroenterology. 2011;141(4):1249-53.

22. Mikolasevic I, Milic S, Turk Wensveen T, Grgic I, Jakopcic I, Stimac D, et al. Nonalcoholic fatty liver disease - A multisystem disease? World Journal of Gastroenterology. 2016;22(43):9488-505.

23. Papamiltiadous ES, Roberts SK, Nicoll AJ, Ryan MC, Itsiopoulos C, Salim A, et al. A randomised controlled trial of a Mediterranean Dietary Intervention for Adults with Non Alcoholic Fatty Liver Disease (MEDINA): study protocol. BMC Gastroenterology. 2016;16(1):1.

24. NHMRC. Australian Guidelines to reduce Health Risks from Drinking Alcohol. National Health and Medical Research Council; 2009.

25. WHO. Obesity and overweight [Fact Sheet]. World Health Organisation; 2016 [updated June 2016. Available from: http://www.who.int/mediacentre/factsheets/fs311/en/.

26. Salgado ALFdA, Carvalho Ld, Oliveira AC, Santos VNd, Vieira JG, Parise ER. Insulin resistance index (HOMA-IR) in the differentiation of patients with non-alcoholic fatty liver disease and healthy individuals. Arquivos de gastroenterologia. 2010;47(2):165-9.

27. Stål P. Liver fibrosis in non-alcoholic fatty liver disease-diagnostic challenge with prognostic significance. World Journal of Gastroenterology: WJG. 2015;21(39):11077.

28. Roulot D, Czernichow S, Le Clésiau H, Costes J-L, Vergnaud A-C, Beaugrand M. Liver stiffness values in apparently healthy subjects: influence of gender and metabolic syndrome. Journal of hepatology. 2008;48(4):606-13.

29. Bergqvist CJ, Skoien R, Horsfall L, Clouston AD, Jonsson JR, Powell EE. Awareness and opinions of non-alcoholic fatty liver disease by hospital specialists. Internal Medicine Journal. 2013;43(3):247-53.

30. Nascimbeni F, Pais R, Bellentani S, Day CP, Ratziu V, Loria P, et al. From NAFLD in clinical practice to answers from guidelines. Journal of Hepatology. 2013;59(4):859-71.

31. Bazick J, Donithan M, Neuschwander-Tetri BA, Kleiner D, Brunt EM, Wilson L, et al. Clinical Model for NASH and Advanced Fibrosis in Adult Patients With Diabetes and NAFLD: Guidelines for Referral in NAFLD. Diabetes Care. 2015.

32. Browning JD, Szczepaniak LS, Dobbins R, Nuremberg P, Horton JD, Cohen JC, et al. Prevalence of hepatic steatosis in an urban population in the United States: Impact of ethnicity. Hepatology. 2004;40(6):1387-95. 
33. Fracanzani AL, Valenti L, Bugianesi E, Andreoletti M, Colli A, Vanni E, et al. Risk of severe liver disease in nonalcoholic fatty liver disease with normal aminotransferase levels: a role for insulin resistance and diabetes. Hepatology. 2008;48(3):792-8.

34. Loria P, Marchesini G, Nascimbeni F, Ballestri S, Maurantonio M, Carubbi F, et al.

Cardiovascular risk, lipidemic phenotype and steatosis. A comparative analysis of cirrhotic and noncirrhotic liver disease due to varying etiology. Atherosclerosis. 2014;232(1):99-109.

35. Paschos $P$, Paletas K. Non alcoholic fatty liver disease and metabolic syndrome. Hippokratia. 2009;13(1):9-19.

36. Lonardo A, Bellentani S, Argo CK, Ballestri S, Byrne CD, Caldwell SH, et al. Epidemiological modifiers of non-alcoholic fatty liver disease: Focus on high-risk groups. Digestive and Liver Disease. 2015;47(12):997-1006.

37. Australia GSo. The economic cost and health burden of liver diseases in Australia. Sydney, Australia: The Gastroenterological Society of Australia/Australian Liver Association. 2013.

38. Younossi ZM, Koenig AB, Abdelatif D, Fazel Y, Henry L, Wymer M. Global epidemiology of nonalcoholic fatty liver disease-Meta-analytic assessment of prevalence, incidence, and outcomes. Hepatology. 2016;64(1):73-84.

39. Angelico F, Del Ben M, Conti R, Francioso S, Feole K, Fiorello S, et al. Insulin resistance, the metabolic syndrome, and nonalcoholic fatty liver disease. The Journal of Clinical Endocrinology \& Metabolism. 2005;90(3):1578-82.

40. Targher G, Bertolini L, Padovani R, Rodella S, Tessari R, Zenari L, et al. Prevalence of Nonalcoholic Fatty Liver Disease and Its Association With Cardiovascular Disease Among Type 2 Diabetic Patients. Diabetes Care. 2007;30(5):1212-8.

41. Hamaguchi M, Kojima T, Takeda N, Nakagawa T, Taniguchi H, Fujii K, et al. The metabolic syndrome as a predictor of nonalcoholic fatty liver disease. Annals of internal medicine. 2005;143(10):722-8.

42. Ong JP, Elariny H, Collantes R, Younoszai A, Chandhoke V, Reines HD, et al. Predictors of nonalcoholic steatohepatitis and advanced fibrosis in morbidly obese patients. Obesity surgery. 2005;15(3):310-5.

43. Suzuki A, Angulo P, Lymp J, St Sauver J, Muto A, Okada T, et al. Chronological development of elevated aminotransferases in a nonalcoholic population. Hepatology. 2005;41(1):64-71.

44. Neuschwander-Tetri BA, Clark JM, Bass NM, Van Natta ML, Unalp-Arida A, Tonascia J, et al. Clinical, laboratory and histological associations in adults with nonalcoholic fatty liver disease. Hepatology. 2010;52(3):913-24.

45. Gupte P, Amarapurkar D, Agal S, Baijal R, Kulshrestha P, Pramanik S, et al. Non-alcoholic steatohepatitis in type 2 diabetes mellitus. Journal of gastroenterology and hepatology. 2004;19(8):854-8.

46. Smith BW, Adams LA. Nonalcoholic fatty liver disease and diabetes mellitus: pathogenesis and treatment. Nature Reviews Endocrinology. 2011;7(8):456-65. 
Table 1: Liver Diagnoses at each clinic site

\begin{tabular}{lccc}
\hline & Site 1 & Site 2 & Total \\
\hline Patients screened $(n)$ & 892 & 1158 & 2050 \\
\hline NAFLD n (\%) & $44(4.9)$ & $104(9.0)$ & $148(7.2)$ \\
& & & \\
\hline Hepatitis B n (\%) & $29(3.3)$ & $379(32.7)$ & $408(19.9)$ \\
\hline History ETOH n (\%) & $223(25)$ & $145(12.5)$ & $368(18)$ \\
\hline Hepatitis C n (\%) & $83(9.3)$ & $178(15.4)$ & $261(12.7)$
\end{tabular}

Abbreviations: NAFLD: Non Alcoholic Fatty liver disease, ETOH: ethanol 
Supplementary Table : A breakdown of the histological staging using Brunt score for a subset of patients with NAFLD diagnosis.

\begin{tabular}{|c|c|c|c|c|}
\hline Case number & Steatosis (0-3) & $\begin{array}{l}\text { Lobular } \\
\text { inflammation (0- } \\
\text { 3) }\end{array}$ & Ballooning (0-2) & Brunt score (0-8) \\
\hline 1 & 3 & 2 & 2 & 7 \\
\hline 2 & 3 & 1 & 2 & 6 \\
\hline 3 & 3 & $1-2$ & 1 & 6 \\
\hline 4 & 2 & 1 & 2 & 4 \\
\hline 5 & 3 & 1 & 0 & 4 \\
\hline 6 & 3 & 0 & 0 & 3 \\
\hline 7 & 2 & 2 & 2 & 6 \\
\hline 8 & 2 & 1 & 2 & 5 \\
\hline 9 & 2 & 1 & 2 & 5 \\
\hline
\end{tabular}

This article is protected by copyright. All rights reserved. 
George Elena (Orcid ID: 0000-0002-1385-2371)

Table 2: NAFLD patient characteristics for overall cohort and LSM score categories by risk of cirrhosis ${ }^{25}$

\begin{tabular}{|c|c|c|c|c|c|c|c|c|}
\hline & & & $\begin{array}{l}\text { Overall NAFLD } \\
\text { cohort }\end{array}$ & $\begin{array}{l}<9.6 \mathrm{kPa} \\
n=77\end{array}$ & & $\begin{array}{l}\geq 9 . \\
n=4\end{array}$ & $\begin{array}{l}\mathrm{kPa} \\
0\end{array}$ & \\
\hline & $\begin{array}{l}\text { Reference } \\
\text { Range }\end{array}$ & $n$ & Mean $\pm S D$ & $n$ & Mean $\pm S D$ & $n$ & Mean $\pm S D$ & p value \\
\hline Age (yrs) & - & 148 & $55.8 \pm 14.5$ & 77 & $52.6 \pm 14.1$ & 40 & $62.1 \pm 11.5$ & $0.0005^{*}$ \\
\hline Height $(\mathrm{cm}) \dagger$ & - & 124 & $163.0(16.5)$ & 69 & $\begin{array}{l}165.0 \\
(10.0)\end{array}$ & 35 & $162.0(18.5$ & 0.455 \\
\hline Weight (kg) & - & 130 & $85.0 \pm 20.4$ & 72 & $84.9 \pm 21.1$ & 37 & $86.4 \pm 20.7$ & 0.565 \\
\hline BMI (kg/m2) & $\begin{array}{l}18.5-25 \\
\mathrm{~kg} / \mathrm{m} 2\end{array}$ & 124 & $30.7 \pm 5.9$ & 69 & $30.1 \pm 5.9$ & 36 & $32.0 \pm 6.1$ & 0.077 \\
\hline LSM Score $(\mathrm{kPa}) \dagger$ & & 117 & $6.5(6.0)$ & & & & & \\
\hline Glucose $(\mathrm{mmol} / \mathrm{L}) \dagger$ & $3.5-6.0$ & 114 & $5.9(1.7)$ & 61 & $5.5(1.2)$ & 29 & $6.2(5.3)$ & $0.007^{*}$ \\
\hline HbA1c (\%) & $<6.0$ & 33 & $6.3 \pm 0.8$ & 21 & $6.2 \pm 0.8$ & 11 & $6.4 \pm 0.8$ & 0.350 \\
\hline $\operatorname{ALT}(U / L) \dagger$ & $\begin{array}{l}\mathrm{M}:<30 \\
\mathrm{~F}:<20\end{array}$ & $\begin{array}{l}\text { M: } 64 \\
F: 79\end{array}$ & $\begin{array}{l}\mathrm{M}: 47.0(34.3) \\
F: 36.0(28.0)\end{array}$ & 74 & $41.0(33.0)$ & 39 & $46.0(31.5)$ & 0.354 \\
\hline
\end{tabular}

This article is protected by copyright. All rights reserved. 


\begin{tabular}{|c|c|c|c|c|c|c|c|c|}
\hline & & 143 & $42.0(38.0)$ & & & & & \\
\hline $\operatorname{ALP}(U / L) \dagger$ & $30-110$ & 136 & $86.5(19.3)$ & 71 & $85.0(19.0)$ & 36 & $92.0(75.0)$ & 0.294 \\
\hline \multirow{3}{*}{ AST $(U / L) \dagger$} & \multirow{3}{*}{$\begin{array}{l}\mathrm{M}:<35 \\
\mathrm{~F}:<30\end{array}$} & M: 57 & M: 33 (18.8) & \multirow{3}{*}{58} & \multirow{3}{*}{$25.5(26.0)$} & \multirow{3}{*}{33} & \multirow{3}{*}{$41.0(62.0)$} & \multirow{3}{*}{$0.0005^{*}$} \\
\hline & & F: 58 & $F: 27(20.3)$ & & & & & \\
\hline & & 115 & $32.0(43.5)$ & & & & & \\
\hline \multirow{3}{*}{ GGT $(U / L) \dagger$} & \multirow{3}{*}{$\begin{array}{l}\mathrm{M}:<62 \\
\mathrm{~F}:<38\end{array}$} & $M: 62$ & M: 67.5 (112.3) & \multirow{3}{*}{71} & \multirow{3}{*}{$66.0(72.0)$} & \multirow{3}{*}{37} & \multirow{3}{*}{$86.0(131.0)$} & \multirow{3}{*}{0.10} \\
\hline & & F: 75 & F: $72.0(90.0)$ & & & & & \\
\hline & & 137 & $69.0(99.0)$ & & & & & \\
\hline Bilirubin (umol/L) $†$ & $<21$ & 137 & $10.0(6.8)$ & 71 & $10.0(7.0)$ & 37 & $12.0(8.5)$ & 0.114 \\
\hline Insulin (mIU/L) † & $<25$ & 38 & $13.8(12.4)$ & 23 & $13.0(14.1)$ & 10 & $16.5(16.0)$ & 0.346 \\
\hline $\begin{array}{l}\text { Total Cholesterol } \\
(\mathrm{mmol} / \mathrm{L})\end{array}$ & $<5.5$ & 127 & $4.9 \pm 1.2$ & 67 & $5.1 \pm 1.1$ & 34 & $4.6 \pm 1.4$ & $0.009^{*}$ \\
\hline $\mathrm{HDL}(\mathrm{mmol} / \mathrm{L})$ & $>1.0$ & 113 & $1.3 \pm 0.4$ & 60 & $1.3 \pm 0.4$ & 31 & $1.2 \pm 0.4$ & 0.618 \\
\hline LDL (mmol/L) & $<3.5$ & 110 & $2.8 \pm 1.1$ & 57 & $3.1 \pm 1.0$ & 31 & $2.6 \pm 1.2$ & $0.015^{*}$ \\
\hline TGs $(\mathrm{mmol} / \mathrm{L}) \dagger$ & $<2.0$ & 124 & $1.5(0.7)$ & 65 & $1.6(0.6)$ & 33 & $1.5(1.5)$ & 0.643 \\
\hline HOMA-IR $(\mathrm{mmol} / \mathrm{L}) \dagger$ & $<2.0$ & 32 & $4.2(3.2)$ & 21 & $3.1(3.0)$ & 8 & $5.4(5.5)$ & $0.040^{*}$ \\
\hline Co morbidities by Site & & & & & y LSM & & & \\
\hline
\end{tabular}

This article is protected by copyright. All rights reserved. 


\begin{tabular}{|c|c|c|c|c|c|c|}
\hline & Total \% & Site $1 \%$ & Site $2 \%$ & $n(\%)$ & $n(\%)$ & p value \\
\hline T2DM & 43.9 & 55 & 39 & $25(33)$ & $23(58)$ & $0.009 *$ \\
\hline HTN & 52 & 55 & 51 & $33(43)$ & $26(65)$ & $0.023^{*}$ \\
\hline CVD & $19.6^{* *}$ & 9 & 24 & $10(13)$ & $9(23)$ & 0.19 \\
\hline Depression & 22.3 & 20 & 23 & - & - & - \\
\hline IGT & 10.1 & 16 & 8 & $12(16)$ & $1(3)$ & $0.033^{*}$ \\
\hline HCC & 2.7 & 4.5 & 1.9 & - & - & - \\
\hline Deranged Lipids & $33.1^{* *}$ & 18 & 7 & $27(35)$ & $13(33)$ & 0.78 \\
\hline $\begin{array}{l}\text { Obstructive Sleep } \\
\text { Apnoea }\end{array}$ & 10.1 & 50 & 29 & - & - & - \\
\hline \multicolumn{7}{|l|}{ Medications } \\
\hline OHAs & $50 * *$ & 29 & 35.1 & $20(26)$ & $19(48)$ & $0.019^{*}$ \\
\hline Statins & 36 & 28 & 30.4 & $19(25)$ & $12(30)$ & 0.54 \\
\hline Antihypertensives & 36 & 38 & 37.2 & $22(29)$ & $19(18)$ & $0.042^{*}$ \\
\hline
\end{tabular}

Non parametric data presented as median (IQR).

$* p<0.05$ statistically significant **Between site comparison using $\chi^{2}, p<0.05$

Abbreviations: BMI: Body Mass Index, ALT: alanine aminotransferase, ALP: alkaline phosphatase, AST: aspartate aminotransferase, GGT: Gamma-

glutamyltransferase, HDL: High Density Lipoproteins, LDL: Low density Lipoproteins, TG: Triglycerides, HOMA-IR: Homeostatic Model of Assessment- IR,

This article is protected by copyright. All rights reserved. 
T2DM: Type 2 Diabetes Mellitus, HTN: Hypertension, CVD: CVD, IGT: Impaired Glucose tolerance, HCC: hepatocellular carcinoma, OHA's: Oral Hypoglycaemic agents 
George Elena (Orcid ID: 0000-0002-1385-2371)

Table 3: Correlations between LSM score and other variables

\begin{tabular}{|c|c|c|c|c|c|c|c|c|c|c|c|c|c|}
\hline Variables & Glucose & BMI & Age & Cholesterol & $L D L$ & $H D L$ & TG & $A L T$ & $A L P$ & AST & GGT & HOMA & Insulin \\
\hline LSM Score & & & & & & & & & & & & & \\
\hline$r$ & 0.19 & 0.27 & 0.28 & -0.27 & -0.33 & -0.02 & -0.11 & 0.20 & 0.08 & 0.42 & 0.17 & 0.49 & 0.30 \\
\hline p & 0.07 & $0.005^{*}$ & $0.002^{*}$ & 0.007 & $0.002^{*}$ & 0.85 & 0.29 & $0.03^{*}$ & 0.44 & $0.0005^{*}$ & 0.09 & $0.008^{*}$ & 0.09 \\
\hline
\end{tabular}

*significance indicated with a $p<0.05$.

Abbreviations: BMI: Body Mass Index, ALT: alanine aminotransferase, ALP: alkaline phosphatase, AST: aspartate aminotransferase, GGT: Gamma-

glutamyltransferase, HDL: High Density Lipoproteins, LDL: Low density Lipoproteins, TG: Triglycerides, HOMA-IR: Homeostatic Model of Assessment- IR.

This article is protected by copyright. All rights reserved. 


\section{Abstract}

Background: Non- alcoholic fatty liver disease (NAFLD) is the commonest liver disease globally with increased rates in high risk populations including type 2 diabetes and obesity. The condition increases the risk of end stage liver disease, hepatocellular carcinoma and allcause mortality. NAFLD is asymptomatic and often remains undiagnosed as routine screening in high risk groups is not practised.

Aims: The aim of this study was to determine the rates and characteristics of NAFLD patients attending liver clinics at two Melbourne metropolitan hospitals.

Methods: Liver clinics were prospectively screened for ten consecutive months and participants with a diagnosis of NAFLD were further evaluated using pathology and imaging results obtained from medical records.

Results: Of the 2050 patients screened, 148 (7\%) had NAFLD predominantly diagnosed using ultrasound (81\%). NAFLD patients were obese (mean BMI $30.7 \pm 5.9 \mathrm{~kg} / \mathrm{m}^{2}$ ), insulin resistant (median HOMA 4.2 (3.2) mmol/L), had elevated liver enzymes (ALT median, males 47.0 (34.3), females $36.0(28.0) \mathrm{U} / \mathrm{L}$ ) and $18 \%$ of patients with liver stiffness measure $>12 \mathrm{kPa}$ suggesting a moderate probability of cirrhosis. Patients with liver stiffness measure $\geq 9.6 \mathrm{kPa}$ had significantly higher: glucose (median 5.5 (1.2) vs. 6.2 (5.3) mmol/L, $p=0.007$ ), AST levels (median 25.5 (26.0) vs. 41.0 (62.0) u/L, p=0.0005) and HOMA (3.1 (3.0) vs. 5.4 (5.5) mmol/L, $p=0.040)$.

Conclusions: NAFLD constituted a minority of liver clinic patients, most were obese, insulin resistant, hypertensive and many had an elevated liver stiffness measurement. NAFLD poses 
added adverse health outcomes to high risk patients and therefore early detection is warranted.

Key words: Non- alcoholic fatty liver disease, non-alcoholic steatohepatitis, liver disease, prevalence, metabolic syndrome 
Figure 1: Screening and recruitment process for characterising patient diagnoses

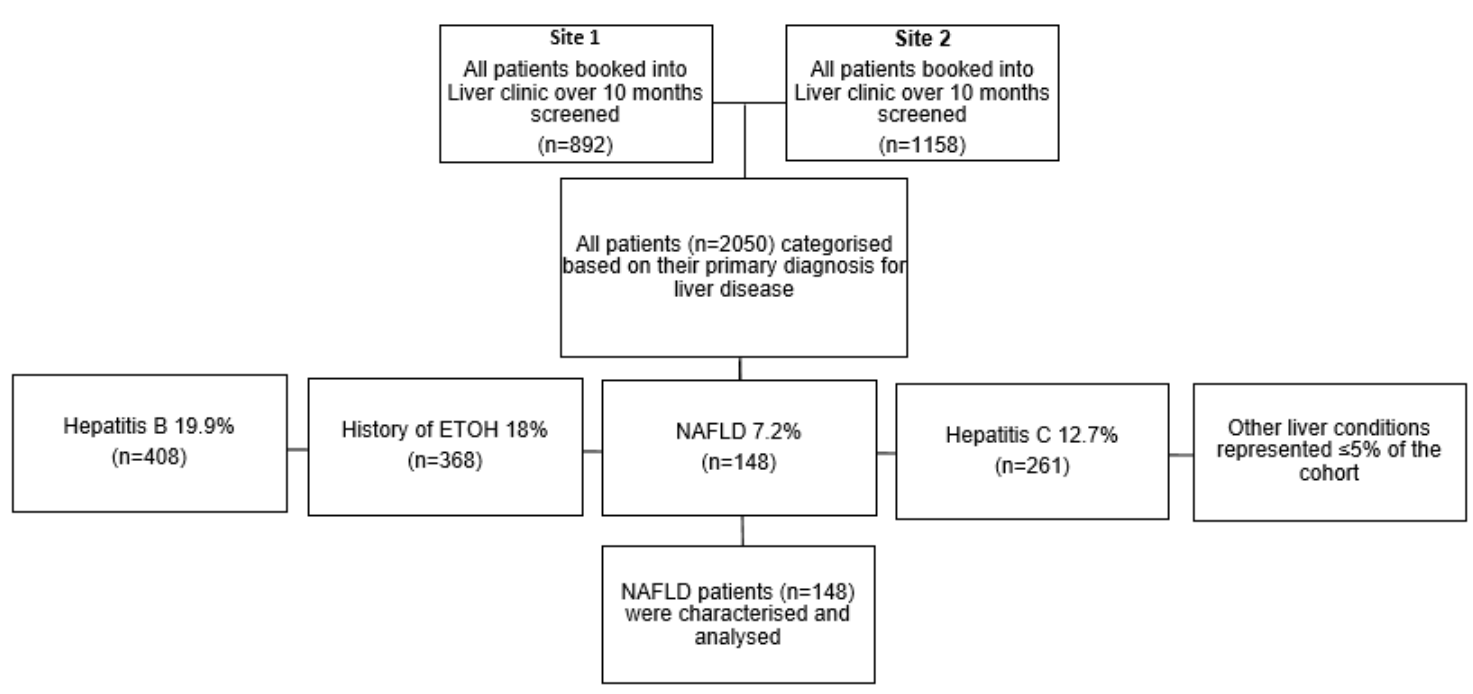

This article is protected by copyright. All rights reserved. 


\title{
Non Alcoholic Fatty Liver Disease Patients Attending Two Metropolitan Hospitals in Melbourne, Australia; High Risk Status and Low Prevalence
}

Running title: NAFLD clinical prevalence and severity

\author{
Elena S George ${ }^{1,2,3}$, Stuart K Roberts ${ }^{4}$, Amanda J Nicoll ${ }^{5}$, Anjana Reddy ${ }^{1}$,Tonya Paris ${ }^{1}$, \\ Catherine Itsiopoulos ${ }^{1}$, Audrey C Tierney ${ }^{1,2,5}$
}

1. Department of Rehabilitation, Nutrition and Sport, La Trobe University, Bundoora, VIC, Australia, 2. Department of Nutrition, Alfred Health, Commercial Rd, Prahran, VIC, Australia, 3. School of Exercise and Nutrition Sciences, Deakin University, Geelong, Australia, 4. Department of Gastroenterology, Alfred Health, Commercial Rd, Prahran, VIC, Australia, 4. Department of Gastroenterology, Eastern Health, Arnold Street, Box Hill, VIC, Australia, 5. Department of Clinical Therapies, University of Limerick, Limerick, V94 T9PX, Ireland.

Corresponding author: Elena S George, B Food Sc \& Nutr (Hons), MDiet

Building J, Deakin University, 221 Burwood Hwy, Burwood VIC 3125, Telephone: +61 (0) 3 9246 8622, Email: Elena.George@deakin.edu.au

Author details (positions at time of submission): Elena S George: Honorary Research Fellow La Trobe University, Lecturer Deakin University, Stuart K Roberts: Head of Hepatology, Alfred Health, Amanda J Nicoll: Director Gastroenterology, Eastern Health, Anjana J Reddy: PhD candidate La Trobe University, Tonya Paris: Dietitian, Catherine Itsiopoulos: Head of School, Allied Health, La Trobe University, Audrey Tierney: Senior Lecturer La Trobe University and Limerick University.

Requests for reprints should be requested from the corresponding author.

This article is protected by copyright. All rights reserved. 
Conflict of interest: None declared.

Contribution: ESG conceptualised the study. ESG, AR and TP were involved in data collection. ESG drafted the manuscript. All authors provided intellectual input and critically reviewed the manuscript.

Source of funding: This work was supported by an Australian Government Research Training Program Scholarship (ESG).

\section{Word Count:}

Abstract- 247

Manuscript- 3158

This article is protected by copyright. All rights reserved. 


\section{University Library}

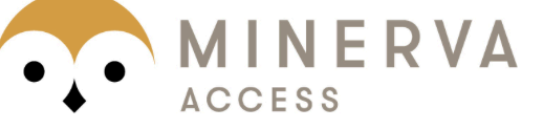

A gateway to Melbourne's research publications

Minerva Access is the Institutional Repository of The University of Melbourne

Author/s:

George, ES;Roberts, SK;Nicoll, AJ;Reddy, A;Paris, T;Itsiopoulos, C;Tierney, AC

Title:

Non-alcoholic fatty liver disease patients attending two metropolitan hospitals in Melbourne, Australia: high risk status and low prevalence

Date:

2018-11-01

\section{Citation:}

George, E. S., Roberts, S. K., Nicoll, A. J., Reddy, A., Paris, T., Itsiopoulos, C. \& Tierney, A. C. (2018). Non-alcoholic fatty liver disease patients attending two metropolitan hospitals in Melbourne, Australia: high risk status and low prevalence. INTERNAL MEDICINE JOURNAL, 48 (11), pp.1369-+. https://doi.org/10.1111/imj.13973.

Persistent Link:

http://hdl.handle.net/11343/284772 